\title{
First Euromar-Market Held in The Netherlands
}

$\mathrm{T}_{\mathrm{H}}$ HE EUROMAR-MARKET, jointly organized by the Netherlands Marine Research Foundation and the "Rijkswaterstaat," took place on board R/V Tyro during September 6-8, 1988, in Scheveningen Harbor, The Netherlands. The market lunctioned as an intensive European "brainstorming session" for about two hundred participants from seventy-seven industries and research organizations and nine European countries.

The Euromar-Market was based on the simple principle that participants presented their "offers" and "demands" for technological expertise in leaflet and poster form. Offers and demands were discussed and proposals for joint international research and development projects were agreed upon. By doing this, the market functioned as a mechanism for large and small European companies and marine research organizations to jointly develop competitive, sophisticated and marketable advanced marine technology and instrumentation.

Euromar was established in London in

Jan H. Stel, Director of the Netherlands Marine Research Foundation. Koningin Sophiestraat 124. 2595 TM. The Hague, the Netherlands.

\author{
By Jan H. Stel
}

1986 with the major goal of enhancing cooperation in research and production of advanced marine technologies. At present. twelve countries participate in the Euromar initiative. The project's objective is to define the needs for advanced instrumentation in specific fields. It is an umbrella project embedding a larger number of subprojects, relating to a Euromar pilot project on environmental measurement systems for resource management in the sea. The pilot project was conceived to develop a conception of and to promote the necessary instrumentation and related standards for national, European and world-wide marine surveillance and information networks. Modules of these systems will be developed under Euromar by cooperation between industry and science for national and international networks.

Working areas of the pilot-project are: - multisensor, remote-controlled modular systems for in situ measurement, eventcontrolled sampling. and real-time date transmission.

- modular, user-oriented software systems based on numerical models.

- marine experimental ecosystems.
- shore-based, shipborne and airborne remote sensing instrumentation and systems. - relevance of remote sensing information to European marine activities.

- instrumentation and techniques for measuring sediment and seabed contributions to environmental management,

- standardization and management of field data acquisition sensors.

- marine environmental data management. referral, distribution and service to users.

- hardware and software relevant to atmospheric input into the sea, and

- carrier systems for the surveillance of the European Sea.

Dr. M. Schulz-Baldes (FRG) is the European general secretary. The two year presidency of the Euromar Board rotates among members. Dr. E.K. Duursma (NL) is the president for 1987-1989. More information can be obtained from the Euromar secretariat, which is located at the Alfred Wegener Institute for Polar and Marine Research, Columbus-Strasse, P.O. Box 120161, D-2850 Bremerhaven, Federal Republic of Germany. $\square$

\section{University of Hawail Offers Graduate Certificate In OCEAN Policy}

SinCE THE spring of 1989, the University of Hawaii at Manoa has offered a graduate certificate program in marine policy. Recognizing that wise and proper management of ocean resources requires professionals with multi-disciplinary and interdisciplinary training in the natural and social sciences, the certificate program is designed to complement and broaden students" prior education and training in the field of ocean sciences and policy without requiring students to enroll in two advanced degree programs.

For example, a student trained in the natural sciences would choose to enroll in the certificate program "s policy track which might include course work in law, geography, political science and economics. Stu-

Steve Russell, Coordinator, Marine Option Program.

\section{By Steve H. Russell}

dents whose prior education is primarily in law or the social sciences would choose a natural or physical science track, taking courses in oceanography, ocean engineering, geology and geophysics. The certificate program also allows working professionals in the community to earn a certificate without enrolling in a formal degree program.

In addition to the eighteen credits required from the courses mentioned above, attending a seminar and participating in two practica are necessary to earn the certificate.

These practica will take the form of an oceanographic research cruise for students on the policy track and observation of governmental ocean policy legislation over a semester for students choosing the natural or physical science track.
The goals of the Graduate Ocean Policy Certificate Program are to provide the necessary multi-disciplinary and inter-disciplinary education and training to individuals who will become the ocean managers and policy makers in the future. The University of Hawaii's central location in the Pacific Basin. with strong ties to the mainland. Asia, and Pacific island nations, gives it both the opportunity and responsibility to make a substantial contribution to the development of sound ocean policy. The Graduate Ocean Policy Certificate Program offered at the University of Hawaii addresses this challenge.

Information about the program may be obtained from the University of Hawaii at Manoa, Marine Option Program, 1000 Pope Rd. Room 229. Honolulu. HI 96822: Telephone: (808) 948-8433. 